\title{
Comparação de métodos para quantificação de bactérias nitrificantes
}

\author{
Comparison of methods for quantification of nitrifying bacteria \\ Juliana Calabria de Araujo', Ana Paula Campos², Eduardo Carvalho Silva ${ }^{3}$, \\ Renata Côrtes de Oliveira ${ }^{4}$, Carlos Augusto de Lemos Chernicharo ${ }^{5}$
}

\begin{abstract}
口
\section{RESUMO}

A quantificação de bactérias nitrificantes é de extrema importância para o monitoramento de sistemas biológicos de tratamento que promovam a nitrificação. Neste trabalho, 15 amostras de efluentes coletadas em sistema de tratamento por lodos ativados ( $L A)$ foram analisadas de modo a quantificar bactérias nitrificantes por meio de duas técnicas: tubos múltiplos ou técnica do número mais provável (NMP); e hibridação in situ fluorescente (FISH). Os resultados sugerem que houve uma tendência de se obter valores diferentes para bactérias oxidadoras de amônia por meio da NMP em comparação com a FISH. Não obstante, a análise estatística revelou que a diferença de quantificação encontrada entre as técnicas não foi significativa, indicando que ambas podem ser usadas. Para as oxidadoras de nitrito, não foi possível realizar comparação, uma vez que os gêneros que estavam sendo determinados em cada uma das técnicas provavelmente eram diferentes. Sendo assim, as técnicas NMP e FISH se mostraram métodos relativamente simples e adequados para quantificação de microrganismos nitrificantes, com vantagens e limitações inerentes a cada uma.
\end{abstract}

Palavras-chave: bactérias oxidadoras de amônia; bactérias oxidadoras de nitrito; hibridação in situ fluorescente; lodos ativados; número mais provável.

\begin{abstract}
The quantification of nitrifying bacteria is of utmost importance for monitoring biological treatment systems designed to promote nitrification. In this study, 15 activated sludge samples were analyzed in order to quantify nitrifying bacteria by two different methods: the mostprobable number (MPN); and the fluorescence in situ hybridization (FISH). The results suggest that there was a tendency to obtain different values for ammonia-oxidizing bacteria by MPN compared to FISH. However, statistical analysis of these data revealed that the difference found between the two techniques was not significant, indicating that both can be used for quantification of ammonia-oxidizing bacteria. For nitrite-oxidizing bacteria it was not possible to make this comparison, since the bacterial genera that were being determined in each technique were likely different. Thus, MPN and FISH techniques proved to be relatively simple and suitable for quantification of nitrifying microorganisms in sludge samples, each of them with advantages and limitations.
\end{abstract}

Keywords: ammonia-oxidizing bacteria; nitrite-oxidizing bacteria; fluorescence in situ hybridization; activated sludge; most probable number.

\section{INTRODUÇÃO}

O nitrogênio é um composto que está presente em diversos efluentes industriais e domésticos e pode ser tóxico ao ambiente. No esgoto doméstico, a concentração de nitrogênio amoniacal está em torno de $35 \mathrm{mg} \mathrm{N}-\mathrm{NH}_{4}^{+} \cdot \mathrm{L}^{-1}$ (ARAUJO et al., 2010), considerada extremamente baixa quando comparada com efluentes como de indústria frigorífica, $170 \mathrm{mg} \mathrm{N}-\mathrm{NH}_{4}^{+} . \mathrm{L}^{-1}$ (REGINATTO et al., 2005), ou de coqueria, de 330 a $650 \mathrm{mg} \mathrm{N}-\mathrm{NH}_{4}{ }^{+} . \mathrm{L}^{-1}$ (TOH \& ASHBOLT, 2002). A remoção de nitrogênio é um aspecto importante do tratamento de águas residuárias, $\mathrm{e}$ geralmente é realizada por processos biológicos tais como nitrificação e desnitrificação. As bactérias nitrificantes têm como principais representantes aquelas pertencentes aos gêneros Nitrosomonas - responsáveis pela oxidação do íon amônio $\left(\mathrm{NH}_{4}^{+}\right)$a nitrito $\left(\mathrm{NO}_{2}^{-}\right)$- e Nitrobacter responsáveis pela oxidação do nitrito a nitrato $\left(\mathrm{NO}_{3}{ }^{-}\right)$. Tendo em vista a

'Doutora em Hidráulica e Saneamento, Escola de Engenharia de São Carlos (EESC), Universidade de São Paulo (USP). Professora adjunta do Departamento de Engenharia Sanitária (DESA), Universidade Federal de Minas Gerais (UFMG) - Belo Horizonte (MG), Brasil.

²Bióloga e Mestre em Saneamento, Meio Ambiente e Recursos Hídricos, UFMG - Belo Horizonte (MG), Brasil.

${ }^{3}$ Biólogo, UFMG - Belo Horizonte (MG), Brasil.

${ }^{4}$ Bióloga, Pontifícia Universidade Católica de Minas Gerais (PUC-Minas) - Belo Horizonte (MG), Brasil.

${ }^{5}$ Doutor em Engenharia Ambiental, Universidade de Newcastle upon Tyne. Professor associado do DESA/UFMG - Belo Horizonte (MG), Brasil.

Endereço para correspondência: Juliana Calabria de Araújo - Universidade Federal de Minas Gerais - Avenida Antonio Carlos, 6.627 , bloco 1, sala 4.528 - Escola de Engenharia - Campus Pampulha - 31270-901 - Belo Horizonte (MG), Brasil. E-mail: juli.calabria@ig.com.br

Recebido: 05/09/12 - Aceito: 03/02/17 - Reg. ABES: 101256 
importância ambiental desses microrganismos, torna-se relevante a sua quantificação, principalmente na monitoração de sistemas biológicos de tratamento desenvolvidos para promover a nitrificação.

Tradicionalmente, as bactérias nitrificantes vêm sendo quantificadas por meio da técnica convencional dependente de cultivo - tubos múltiplos ou técnica do número mais provável (NMP) - apesar da possibilidade de esse método subestimar essa população, devido à característica das bactérias de formarem aglomerados, e/ou da diferença de cultivo entre as diferentes espécies de oxidadoras de amônia. A NMP permite estimar a densidade da população microbiana presente sem contagem individual das células ou colônias. Microbiologistas frequentemente estimam o tamanho das populações com base na maior diluição na qual o crescimento pode ser obtido. Então, se o crescimento foi observado na diluição $10^{-4}$, mas não na $10^{-5}$, o número de células viáveis é estimado estar entre $10^{4} \mathrm{e} 10^{5}$. O teste de várias alíquotas de uma série de diluições sucessivas, junto com cálculos estatísticos e interpolações, fornecem estimativas muito mais precisas (ALEXANDER, 1982 apud KIELING, 2004). Além disso, esse método detecta e estima a população dos diferentes grupos de microrganismos nas amostras. Pressupõe-se que, na incubação de cada tubo que recebeu o inóculo, os microrganismos apresentarão crescimento, acarretando mudanças características no meio de cultura. Como ocorrem resultados negativos em alguns dos tubos, a NMP do microrganismo na amostra analisada pode ser estimado a partir do número e da distribuição de tubos que apresentaram reação positiva.

A técnica de hibridação in situ fluorescente (fluorescence in situ hybriditazion - FISH) é um método direto para contagem de células, que consiste na utilização de sondas de oligonucleotídeos marcadas com corante fluorescente e complementares a uma determinada região do RNAr 16S. Cada célula ativa contém entre $10^{3}$ e $10^{5}$ ribossomos, e parte destes são os RNAs ribossomais. Algumas regiões dos RNAs ribossomais estão acessíveis para a hibridação, indicando que é possível ligar a sonda a certa região do RNAr 16S. Dependendo das sondas utilizadas, a FISH pode ser usada para detectar microrganismos de diferentes níveis filogenéticos (diferentes grupos funcionais e diferentes gêneros). Para a hibridação in situ fluorescente, o alvo das sondas marcadas é o RNAr 16S ou 23S. Dessa forma, a intensidade do sinal obtido pela hibridação é dependente da atividade metabólica da célula no momento da fixação e, portanto, da taxa de crescimento da célula.

Assim sendo, a análise in situ de populações bacterianas pela técnica FISH é mais apropriada para a análise de bactérias fisiologicamente ativas, ou seja, aquelas encontradas em ambientes ricos em nutrientes (como sistemas de tratamento de águas residuárias, por exemplo) e não em ambientes pobres em nutrientes (como solo). Devido à grande especificidade da interação da sonda com o RNAr alvo, o limite de detecção da técnica é de $10^{3}$ a $10^{4}$ células por mL (AMANN; LUDWIG; SCHLEIFER, 1995). A FISH vem sendo amplamente empregada para a quantificação de diferentes gêneros de bactérias nitrificantes, tanto oxidadoras de amônia quanto de nitrito em sistemas de tratamento.

O objetivo deste trabalho foi quantificar bactérias nitrificantes presentes em amostras de lodo aeróbio - oriundo de um sistema convencional de lodos ativados (LA) - por meio de NMP e FISH. Os resultados foram comparados e analisados estatisticamente, evidenciando as vantagens e desvantagens de cada uma das técnicas para aplicação na área de saneamento.

\section{MATERIAIS E MÉTODOS}

\section{Amostras}

Com o objetivo de se comparar técnicas distintas de quantificação de bactérias nitrificantes, presentes em sistemas de tratamento de águas residuárias, foram realizadas 15 coletas de amostras de lodo, provenientes do tanque de aeração do sistema de lodos ativados da Estação de Tratamento de Esgoto de Arrudas (ETE Arrudas), da Companhia de Saneamento de Minas Gerais (COPASA), que trata esgoto doméstico da cidade de Belo Horizonte, Minas Gerais. Esse sistema de LA foi escolhido no presente trabalho por se tratar de um sistema em escala real, em que a disponibilidade de amostra de lodo era constante, e pelo fato de que não se tinha informação prévia sobre a atividade nitrificante desse sistema. Consequentemente, os dados gerados neste trabalho foram importantes para se ter maior conhecimento do funcionamento do sistema ao longo do tempo. Posteriormente, as amostras foram submetidas às técnicas NMP e FISH. Cerca de 2 litros de amostra de lodo foram coletados em frascos de plástico (previamente esterilizados em autoclave a $121^{\circ} \mathrm{C}$ por 15 minutos) hermeticamente fechados. As coletas foram realizadas em diferentes épocas, no período de abril de 2008 a dezembro de 2009.

\section{Tubos múltiplos ou número mais provável}

Neste trabalho, foi adotado o método proposto por Alexander e Clark (1982) para análise de solos, o qual foi adaptado para análise de lodos por Kieling (2004). Uma alíquota de $100 \mathrm{~mL}$ da amostra de lodo aeróbio foi macerada em frasco contendo $50 \mathrm{~g}$ de pérolas de vidro, sob agitação manual por 20 minutos e diluída em água de diluição $(1 \mathrm{~mL}$ de $\mathrm{K}_{2} \mathrm{HPO}_{4}$ 0,2 M, e, 0,25 mL de $\mathrm{KH}_{2} \mathrm{PO}_{4}$ 0,2 $\mathrm{M}$ em $250 \mathrm{~mL}$ de água destilada), por meio de diluição seriada.

Para quantificação das bactérias oxidadoras de amônia e das oxidadoras de nitrito, foram utilizados, respectivamente, os meios de cultura amônia-carbonato $\left(0,30 \mathrm{~g}\right.$ de $\left(\mathrm{NH}_{4}\right)_{2} \mathrm{SO}_{4} ; 1,00 \mathrm{~g} \mathrm{~K}_{2} \mathrm{HPO}_{4}$; $0,03 \mathrm{~g}$ de $\mathrm{FeSO}_{4} .7 \mathrm{H}_{2} \mathrm{O} ; 0,30 \mathrm{~g}$ de $\mathrm{NaCL} ; 0,30 \mathrm{~g}$ de $\mathrm{MgSO}_{4} .7 \mathrm{H}_{2} \mathrm{O} ; 3,33$ g de $\mathrm{CaCO}_{3}$, em $1 \mathrm{~L}$ de água destilada) e nitrito-carbonato $(0,006 \mathrm{~g}$ de $\mathrm{KNO}_{2} ; 1,000 \mathrm{~g} \mathrm{~K}_{2} \mathrm{HPO}_{4} ; 0,300 \mathrm{~g}$ de NaCl$; 0,100 \mathrm{~g}$ de $\mathrm{MgSO}_{4} .7 \mathrm{H}_{2} \mathrm{O}$; 
0,030 g de $\mathrm{FeSO}_{4} .7 \mathrm{H}_{2} \mathrm{O} ; 1,000 \mathrm{~g}$ de $\mathrm{CaCO}_{3} ; 0,300 \mathrm{~g} \mathrm{de} \mathrm{CaCl}_{2}$, em $1 \mathrm{~L}$ de água destilada). Foram feitos cinco tubos para cada diluição. Após três semanas de incubação a $28^{\circ} \mathrm{C}$, foi feita a leitura dos tubos utilizando o reagente de nitrato $(50 \mathrm{mg}$ de $(\mathrm{C} 6 \mathrm{H} 5) 2 \mathrm{NH}$ e $25 \mathrm{~mL}$ de $\mathrm{H} 2 \mathrm{SO} 4$ concentrado) e o reagente de Griess-Ilosvay, formado por três soluções diferentes:

- solução a. 0,6 g de ácido sulfanílico, 20,0 mL de $\mathrm{HCl}$ concentrado e completar para 100,0 mL água destilada;

- solução b. 0,6 g de alfa-naftilamina, $1,0 \mathrm{~mL}$ de $\mathrm{HCl}$, completar para 100,0 $\mathrm{mL}$ de água;

- solução c. 16,4 g de CH3COONa.3H2O em 100,0 mL deágua destilada.

De acordo com o número de tubos que apresentaram resultados positivos nas cinco repetições de cada diluição, consultou-se a tabela de NMP (AWWA; APHA; WEF, 2005), encontrando o valor de NMP. $\mathrm{mL}^{-1}$ de oxidadoras de amônia e de oxidadoras de nitrito, na amostra inoculada.

\section{Hibridação in situ fluorescente}

Para a preparação das amostras e posterior hibridação, foi seguido o protocolo de Amann, Ludwig e Schleifer (1995). Cerca de $2 \mathrm{~mL}$ de amostra do lodo ativado foram fixados em solução de paraformaldeído $4 \%$ em tampão fosfato de sódio (PBS $130 \mathrm{mM}$ de $\mathrm{NaCl}, 7 \mathrm{mM}$ de $\mathrm{Na}_{2} \mathrm{HPO}_{4}$, $3 \mathrm{mM}$ de $\left.\mathrm{NaH}_{2} \mathrm{PO}_{4} ; \mathrm{pH} 7,2\right)$ e posteriormente hibridados com as sondas descritas no Quadro 1, na qual é apresentada, ainda, a concentração de formamida e de solução de $\mathrm{NaCl}$ utilizada para cada uma delas e sua respectiva especificidade. Após a hibridação, as amostras foram coradas com solução de DAPI (4,6-diamidino-2-fenilindol) a $10 \mathrm{mg} \cdot \mathrm{mL}^{-1}$, e observadas em microscópio de fluorescência (Olympus BX-50) equipado com câmera colorida refrigerada (QcolorR5C). Após a contagem, foi feita uma estimativa do número total de células por $\mathrm{mL}$ de amostra e ainda do número de células hibridadas por $\mathrm{mL}$.

\section{Análise estatística dos resultados}

Na comparação do número de bactérias nitrificantes nas amostras, determinadas por NMP e FISH, foi aplicado o teste $t$ de Wilcoxon para amostras pareadas, que é um equivalente do teste $t$ de Student para dados com distribuição não normal. Como tais contagens foram preparadas a partir de uma mesma amostra de LA a suposição do pareamento se aplica, apesar de as metodologias serem distintas. A análise estatística dos dados foi realizada utilizando o software Statistica 6.1 (versão 2003). Nesta análise, foi adotado um nível de significância $(\alpha)$ igual a $5 \%$.

\section{RESULTADOS E DISCUSSÃO}

A comparação dos resultados da quantificação de bactérias oxidadoras de amônia e de nitrito em 15 amostras de lodo aeróbio, obtidos por meio das técnicas NMP e FISH, é apresentada no Quadro 2. Pode-se verificar que, com a técnica FISH, foi encontrado um número maior de bactérias Nitrosomonas por $\mathrm{mL}$ de lodo (da ordem de $10^{1}$ a $10^{2}$ células a mais por $\mathrm{mL}$ ) em 6 das 15 amostras analisadas, quando comparado com o valor encontrado pela técnica de NMP (Quadro 2). Esses resultados estão de acordo com aqueles obtidos por Konuma et al. (2001) e Schmidt et al. (2002). Nesse último trabalho, os autores verificaram pela FISH um número maior de bactérias Nitrosomonas por $\mathrm{mL}$ de lodo (da ordem de $10^{1}$ a $10^{2}$ ), quando comparado com os valores encontrados pela NMP, o que poderia indicar que a técnica dos tubos múltiplos subestima a quantidade de bactérias oxidadoras de amônia na amostra. Além disso, o trabalho de Schmidt et al. (2002) mostrou que, quando a NMP foi usada para quantificar bactérias oxidadoras de amônia, os resultados foram da ordem de $10^{2}$ e $10^{3}$ células. $\mathrm{mL}^{-1}$; no entanto, essas mesmas bactérias não foram detectadas por meio da FISH, indicando provavelmente que elas deveriam estar presentes, mas abaixo do limite de detecção da técnica. No presente trabalho, fato semelhante pode ter ocorrido quando se utilizou a NMP para quantificar as bactérias oxidadoras de nitrito, ou seja, elas foram determinadas por essa técnica apresentando valores da ordem de $10^{3}$ e $10^{5}$ células.mL $L^{-1}$ (em 6 das 15 amostras analisadas), e para essas, assim como para as demais amostras, células de Nitrobacter não foram detectadas por meio da técnica FISH. A detecção com FISH (com a sonda específica para Nitrobacter) foi obtida para uma única amostra somente (LA07), como consta do Quadro 2.

Não obstante, para essa mesma amostra (LA07) a determinação de bactérias oxidadoras de amônia tanto por NMP quanto por FISH apresentou resultado na mesma ordem de grandeza. Já o grupo de amostras de LA08 a LA15 apresentou valores de bactérias oxidadoras de amônia

Quadro 1 - Sondas de oligonucleotídeos utilizadas na hibridação in situ fluorescente.

\begin{tabular}{|c|c|c|c|c|c|}
\hline Sonda* & Especificidade & Sequência 5' - 3' & FA (\%) & $\mathrm{NaCl}(\mathrm{mM})^{\mathrm{b}}$ & Referência \\
\hline Ntspa662 & Nitrospira & GGAATTCCGCGCTCCTCT & 35 & 80 & Daims et al. (2000) \\
\hline
\end{tabular}

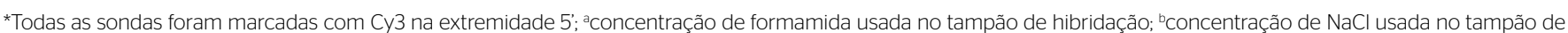
lavagem; FA: formamida. 
(determinados por NMP) superiores (cerca de 3 a 8 ordens de grandeza maior) em relação aos valores obtidos pela técnica FISH (com a sonda Nso190). Sendo assim, foi possível verificar que houve uma tendência de se obter valores maiores para bactérias nitrificantes (preferencialmente do gênero Nitrosomonas) pela técnica NMP em comparação com FISH em oito amostras de LA coletadas em diferentes épocas.

Para verificar se a diferença de quantificação encontrada entre as técnicas era estatisticamente significativa, utilizou-se o teste $t$ de Wilcoxon para amostras pareadas. Após a realização do teste, a hipótese $\mathrm{H}_{0}$ para Nitrosomonas não pôde ser rejeitada, uma vez que foi encontrado um valor $\mathrm{p}$ maior que $0,05(\mathrm{p}=0,272096)$. Portanto, para um universo amostral de 12 amostras por grupo, para Nitrosomonas, o teste sugeriu que não houve diferença estatística significativa entre as contagens de bactérias nitrificantes desse gênero realizadas pelas duas técnicas (FISH e NMP). Portanto, para a determinação de bactérias oxidadoras de amônia, os dois métodos de quantificação são equivalentes estatisticamente a um nível de significância de 5\%, tendo como ressalva o fato de que o universo amostral contemplou 12 amostras.

É importante ressaltar, ainda, que devido ao fato de as contagens das amostras LA09, LA10 e LA15 terem ultrapassado o limite máximo da tabela da NMP, esses resultados não foram incluídos no teste estatístico, mas foram apresentados no Quadro 2. Na Figura 1, por sua vez, é apresentado um exemplo de resultado positivo da hibridação com a sonda Nso190, específica para a maioria das oxidadoras de amônia, da subclasse $\beta$ Proteobacteria, incluindo Nitrosomonas, Nitrosospira, Nitrosovibrio, Nitrosococcus, Nitrosolobus (MOBARRY et al., 1996).

Por meio da técnica FISH, foi possível verificar também que as 15 amostras apresentaram número total de células por $\mathrm{mL}$ bastante próximo (resultados não apresentados), o que é um indício de que os valores obtidos são confiáveis, uma vez que as amostras foram oriundas do mesmo reator, porém de períodos diferentes. Entretanto, o número de bactérias oxidadoras de amônia (células hibridadas

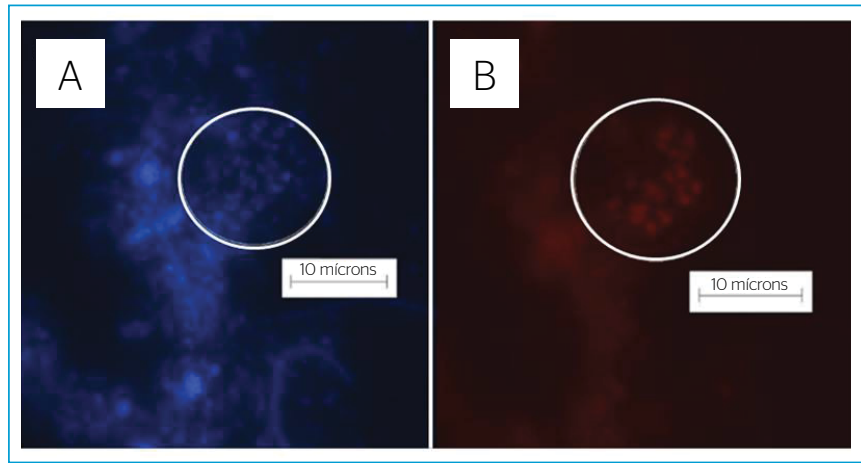

Figura 1 - Análise de hibridação in situ fluorescente das bactérias oxidadoras de amônia. (A) Células coradas com DAPI (4',6'-diamidino2-phenylindol). (B) células hibridadas com a sonda Nso190 (específica para a maioria das oxidadoras de amônia, incluindo Nitrosomonas). O círculo mostra os agregados de células de Nitrosomonas.

Quadro 2 - Resultados da quantificação de bactérias nitrificantes (oxidadoras de amônia e de nitrito) obtidos pelas técnicas número mais provável e hibridação in situ fluorescente.

\begin{tabular}{|c|c|c|c|c|c|}
\hline $\begin{array}{l}\text { Amostra e data } \\
\text { da coleta }\end{array}$ & $\begin{array}{l}\text { NMP de } \\
\text { oxidadoras de amônia } \\
\left.\text { (NMP.mL } L^{-1}\right)\end{array}$ & $\begin{array}{l}\text { FISH com Nso190 } \\
\text { (Nitrosomonas) } \\
\text { (células.mL') }\end{array}$ & $\begin{array}{c}\text { NMP de } \\
\text { oxidadoras de nitrito } \\
\left.\text { (NMP.mL } L^{-1}\right)\end{array}$ & $\begin{array}{l}\text { FISH com Nit3 } \\
\text { (Nitrobacter) } \\
\text { (células.mL') }\end{array}$ & $\begin{array}{l}\text { FISH com Ntspa662 } \\
\text { (Nitrospira) } \\
\text { (células.mL-1) }\end{array}$ \\
\hline LAO1 - 17/O4/08 & $3,50 \times 10^{4}$ & $1,21 \times 10^{6}\left( \pm 6,96 \times 10^{5}\right)^{*}$ & $2,40 \times 10^{3}$ & ND & ND \\
\hline LAO2 - 26/06/08 & $2,40 \times 10^{4}$ & $6,93 \times 10^{6}\left( \pm 1,16 \times 10^{6}\right)$ & $2,20 \times 10^{3}$ & ND & ND \\
\hline LAO3 - O3/09/08 & $3,50 \times 10^{4}$ & $1,45 \times 10^{7}\left( \pm 6,46 \times 10^{6}\right)$ & $2,80 \times 10^{4}$ & ND & ND \\
\hline LAO4 - 25/09/08 & $1,60 \times 10^{5}$ & $1,04 \times 10^{7}\left( \pm 2,01 \times 10^{6}\right)$ & $3,50 \times 10^{4}$ & ND & ND \\
\hline LAO5 - 01/10/08 & $2,40 \times 10^{4}$ & $6,80 \times 10^{6}\left( \pm 1,11 \times 10^{6}\right)$ & $1,60 \times 10^{5}$ & ND & ND \\
\hline LA06 - 14/01/09 & $2,40 \times 10^{5}$ & $1,88 \times 10^{6}\left( \pm 3,23 \times 10^{5}\right)$ & $9,20 \times 10^{4}$ & ND & ND \\
\hline LAO7 - 18/02/09 & $5,40 \times 10^{6}$ & $2,51 \times 10^{6}\left( \pm 5,32 \times 10^{5}\right)$ & $>1,60 \times 10^{7}$ & $4,59 \times 10^{6}\left( \pm 3,20 \times 10^{6}\right)$ & $1,50 \times 10^{7}\left( \pm 3,51 \times 10^{6}\right)$ \\
\hline LA08 - 05/05/09 & $2,40 \times 10^{10}$ & $2,97 \times 10^{7}\left( \pm 5,67 \times 10^{6}\right)$ & $2,80 \times 10^{7}$ & ND & $2,70 \times 10^{7}\left( \pm 1,28 \times 10^{6}\right)$ \\
\hline LA09 - 24/06/09 & $>1,60 \times 10^{11}$ & $1,51 \times 10^{7}\left( \pm 8,44 \times 10^{6}\right)$ & $1,60 \times 10^{11}$ & ND & $3,48 \times 10^{7}\left( \pm 3,63 \times 10^{6}\right)$ \\
\hline LA10 - 14/07/09 & $>1,60 \times 10^{10}$ & $2,55 \times 10^{6}\left( \pm 8,43 \times 10^{6}\right)$ & $1,70 \times 10^{9}$ & ND & $3,22 \times 10^{7}\left( \pm 4,35 \times 10^{6}\right)$ \\
\hline LA11 - 11/08/09 & $9,20 \times 10^{10}$ & $2,98 \times 10^{6}\left( \pm 5,16 \times 10^{6}\right)$ & $4,00 \times 10^{8}$ & ND & $4,43 \times 10^{7}\left( \pm 5,64 \times 10^{6}\right.$ \\
\hline LA12 - 09/09/09 & $1,60 \times 10^{11}$ & $6,20 \times 10^{6}\left( \pm 1,87 \times 10^{6}\right)$ & $3,50 \times 10^{9}$ & ND & $3,16 \times 10^{7}\left( \pm 3,23 \times 10^{6}\right)$ \\
\hline LA13 -08/10/09 & $9,20 \times 10^{10}$ & $5,12 \times 10^{6}\left( \pm 1,40 \times 10^{6}\right)$ & $1,20 \times 10^{7}$ & ND & $1,60 \times 10^{7}\left( \pm 1,45 \times 10^{6}\right)$ \\
\hline LA14 - 29/10/09 & $1,60 \times 10^{14}$ & $2,71 \times 10^{6}\left( \pm 4,02 \times 10^{5}\right)$ & $2,40 \times 10^{13}$ & ND & $3,03 \times 10^{7}\left( \pm 9,01 \times 10^{5}\right)$ \\
\hline LA15 - 17/12/10 & $>1,60 \times 10^{13}$ & $2,21 \times 10^{6}\left( \pm 1,16 \times 10^{6}\right)$ & $1,60 \times 10^{8}$ & ND & $2,32 \times 10^{7}\left( \pm 3,51 \times 10^{6}\right)$ \\
\hline
\end{tabular}

*Os valores entre parênteses representam o desvio-padrão de três contagens diferentes; LA: lodos ativados; ND: não detectado, nenhuma célula apresentou sinal com essas sondas. Esse resultado significa que esses gêneros podem estar ausentes ou presentes - nesse último caso, abaixo do limite de detecção da técnica (10³ a $1 \mathrm{O}^{4}$ células. $\mathrm{mL}^{1}{ }^{1}$ ). 
com a sonda Nso190) variou consideravelmente, de 0,05 a 1,55\%, em relação ao total de células. Essa diferença pode ser decorrente da variação da atividade nitrificante no reator (em diferentes períodos). O sistema de LA da ETE Arrudas não foi projetado, originalmente, para nitrificar - os aeradores não ficam ligados o tempo todo e, portanto, a concentração de oxigênio dissolvido no sistema varia bastante —, mas alguma oxidação da amônia a nitrito ocorre nesse sistema, e isso pôde ser confirmado pela baixa proporção de bactérias oxidadoras de amônia determinadas por meio da técnica FISH. Em reator com atividade nitrificante intensa, Juretschko et al. (1998) verificaram, por meio da FISH, que as bactérias oxidadoras de amônia compreendiam de 10 a $20 \%$ do total de células.

Com relação às bactérias oxidadoras de nitrito, não foi possível realizar a comparação entre as duas técnicas, pois verificou-se que estavam sendo quantificados grupos (gêneros) diferentes de bactérias oxidadoras de nitrito em cada uma delas. A técnica NMP quantifica aquelas oxidadoras de nitrito capazes de crescer no meio de cultura utilizado, sendo que Nitrobacter é o gênero predominante neste meio, porém não o único. Pelo Quadro 2, pode-se verificar que, com a sonda específica para Nitrobacter, esse gênero foi detectado pela técnica FISH somente na amostra LA07, indicando ausência dessas células ou presença abaixo do limite de detecção da técnica nas 14 amostras restantes. Na Figura 2 é apresentado o único resultado positivo obtido da hibridação com a sonda Nit3, específica para Nitrobacter. Posteriormente, quando foi aplicada a sonda específica para Nitrospira (Ntspa662), verificou-se a presença dessas células em 9 das 15 amostras de lodo analisadas (Quadro 2). Esses resultados indicam que foram determinados diferentes gêneros de bactérias oxidadoras de nitrito nas amostras por cada uma das técnicas e que, portanto, a comparação entre estas não se aplica.

Tal resultado é interessante e coerente, e reflete as diferenças inerentes a cada técnica. A NMP está quantificando as oxidadoras de nitrito capazes de crescer no meio de cultura específico - portanto,

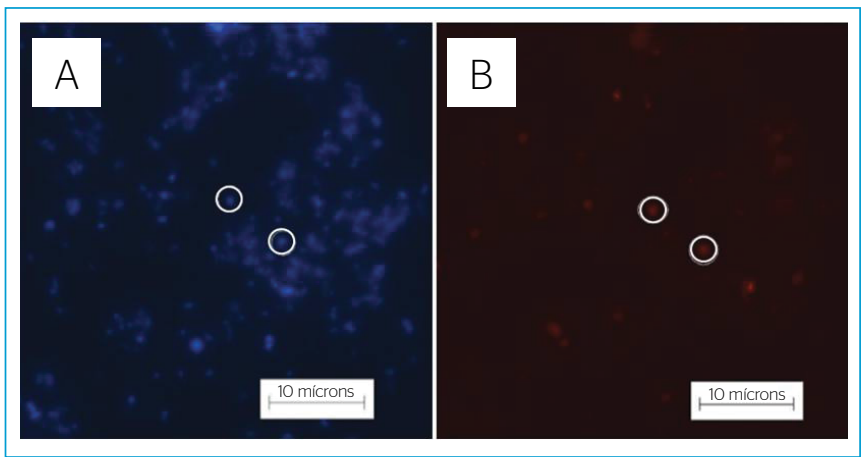

Figura 2 - Análise de hibridação in situ fluorescente das bactérias oxidadoras de nitrito. (A) Células coradas com DAPI $\left(4^{\prime}, 6^{\prime}\right.$-diamidino2-phenylindol). (B) células hibridadas com a sonda Nit3 (específica para Nitrobacter). diferentes gêneros de oxidadoras de nitrito poderiam crescer, dentre eles o gênero Nitrobacter. Segundo a literatura, como Nitrospira cresce muito lentamente comparado ao Nitrobacter, raramente o primeiro gênero é recuperado a partir das técnicas tradicionais de cultivo. Por outro lado, a FISH se baseia na contagem direta com as sondas específicas para cada gênero de oxidadoras de nitrito (como Nitrobacter e Nitrospira); portanto, a soma das porcentagens de hibridação obtidas com cada sonda específica refletiria mais precisamente o número de oxidadoras de nitrito presente em uma amostra. Vale ressaltar que, no presente trabalho, não foram utilizadas as sondas específicas para os outros gêneros de oxidadoras de nitrito por exemplo, o Nitrospina.

Não obstante, os resultados obtidos neste trabalho, para bactérias oxidadoras de nitrito, por meio da técnica FISH, estão de acordo com aqueles obtidos por Juretschko et al. (1998). Os autores verificaram, em um sistema de LA tratando esgoto industrial com concentração elevada de amônia (5.000 mg.L $\mathrm{L}^{-1}$ ), que $9 \%$ do total de células hibridaram com a sonda para Nitrospira, enquanto que células de Nitrobacter não foram detectadas (ou estavam presentes abaixo do limite de detecção da FISH), indicando que nesse sistema células do gênero Nitrospira foram as responsáveis pela oxidação do nitrito à nitrato.

Os autores Wagner et al. (1996) também reportaram baixa atividade in situ de Nitrobacter em vários sistemas nitrificantes naturais e em sistemas de engenharia. Na realidade, tem-se observado que as espécies de Nitrospira descritas até o momento crescem muito devagar em cultura pura quando comparadas com as de Nitrobacter spp. (JURESTCHKO et al., 1998). Assim, especula-se que a importância de Nitrobacter na oxidação de nitrito (no ambiente e em sistemas de engenharia) tenha sido superestimada, já que esse foi o gênero mais comumente encontrado (por meio das técnicas tradicionais de cultivo). Vários trabalhos usando técnicas moleculares - baseados na extração de DNA e na análise de sequências de RNAr 16S - vêm encontrando predominância de Nitrospira em sistemas nitrificantes. Portanto, não é estranho que, em 93\% das amostras de LA da ETE Arrudas analisadas no presente trabalho, não foram detectadas células do gênero Nitrobacter, e sim do gênero Nitrospira. É importante salientar que o sistema de LA desse local não foi projetado, originalmente, para promover a remoção biológica de nitrogênio, mas alguma nitrificação ocorre nesse sistema, assim como a remoção de nitrogênio total — que é, em média, de $50 \%$, segundo Oliveira e Von Sperling (2008). Isso explicaria a ocorrência de Nitrospira na biomassa de LA, uma vez que esse gênero tem constante de afinidade pelo nitrito menor, quando comparado a Nitrobacter (BLACKBURNE et al., 2007), e, portanto, écapaz de sobreviver e se desenvolver em ambientes com baixa concentração de nitrito. De acordo com Daims et al. (2000), na maioria das estações de tratamento de águas residuárias domésticas, a concentração 
de nitrito é pequena, então prevalece o gênero Nitrospira; mas, em estações em que ocorre aumento temporário da concentração de nitrito, ou esta varia espacialmente, ambos os gêneros podem coexistir.

É importante salientar que, apesar de a NMP poder subestimar o número real de bactérias nitrificantes na amostra, devido ao longo tempo de geração das nitrificantes (MATULEWICH; STROM;FINSTEIN, 1975), e ao fato de elas formarem grandes aglomerados de células dentro dos flocos de LA (WAGNER et al., 1995), nem todos os gêneros de bactérias oxidadoras de amônia e de nitrito crescem nas condições de cultivo fornecidas. Não obstante, esta técnica pode ser realizada em qualquer laboratório de microbiologia,não necessitando de equipamentos e reagentes caros. Já a FISH, apesar de também ser relativamente simples, requer equipamentos mais sofisticados, e o custo de cada sonda marcada com composto fluorescente é elevado, o que pode dificultar a sua realização para muitos laboratórios. Uma provável razão para a diferença entre os números encontrados é o fato de a técnica NMP ser um método dependente do cultivo, o que significa que, nela, quantificam-se células que conseguiram crescer ou que se adaptaram ao meio de cultura; e aquelas de difícil cultivo não crescerão. A FISH, ao contrário, é um método direto, independente do cultivo, que, portanto, fornece uma quantificação mais real das bactérias presentes na amostra. Entretanto, o limite de detecção dessa técnica é de cerca de $10^{3}$ a $10^{4}$ células.mL (AMANN; $^{-1}$ (A) LUDWIG; SCHLEIFER, 1995), e populações que estejam abaixo desse valor na amostra podem não ser detectadas.

\section{CONCLUSÕES}

Os resultados obtidos sugerem que houve uma tendência de se obter valores diferentes (maiores ou menores) para bactérias oxidadoras de amônia (preferencialmente do gênero Nitrosomonas) pela técnica NMP em comparação com a FISH. Uma provável razão para os diferentes números encontrados deve-se ao fato de a primeira ser um método dependente do cultivo que, portanto, quantifica células que conseguiram crescer ou que se adaptaram ao meio de cultura, enquanto as de difícil cultivo (ou de crescimento muito lento) não cresceram. Já a FISH é uma técnica direta, independente do cultivo, que detecta as células ativas e que, portanto, deve fornecer quantificação mais precisa das bactérias presentes na amostra em função da sonda usada. Porém, assim como qualquer outra técnica, a FISH também possui um limite de detecção, que nesse caso é de $10^{3}$ a $10^{4}$ células. $\mathrm{mL}^{-1}$ (AMANN; LUDWIG; SCHLEIFER, 1995). Portanto, são detectadas as populações que estejam em concentração igual ou superior a esse valor. Não obstante, a análise estatística dos dados obtidos revelou que a diferença de quantificação encontrada entre as técnicas não foi significativa (a um nível de significância de 5\%), indicando que ambas podem ser usadas para a determinação da abundância de bactérias oxidadoras de amônia.

A comparação entre as técnicas para a quantificação de bactérias oxidadoras de nitrito não foi possível de ser realizada, uma vez que os gêneros que estavam sendo determinados em cada uma delas eram diferentes (provavelmente Nitrobacter por NMP, e Nitrospira por FISH). Sendo assim, as técnicas NMP e FISH se mostraram métodos relativamente simples e adequados para quantificação de microrganismos nitrificantes em amostras provenientes de sistemas de tratamento de águas residuárias, com vantagens e limitações inerentes a cada técnica. É importante ressaltar, ainda, que o sistema de LA da ETE Arrudas não foi projetado para nitrificar; porém, os resultados encontrados neste trabalho sugerem que alguma nitrificação ocorre no local.

Em suma, a escolha da técnica para quantificação das bactérias nitrificantes dependerá, portanto, dos equipamentos e dos recursos disponíveis em cada laboratório, bem como do nível de informação que se deseja obter, uma vez que com a FISH pode-se quantificar os diferentes gêneros de oxidadoras de amônia e nitrito, e com a NMP a quantificação é geral, sem indicação de qual gênero está presente.

\section{AGRADECIMENTOS}

Este trabalho foi financiado pelo Conselho Nacional de Desenvolvimento Científico e Tecnológico (CNPq), pela Fundação de Amparo à Pesquisa do Estado de Minas Gerais (FAPEMIG), e pela Financiadora de Estudos e Projetos (FINEP) ), no âmbito da rede de pesquisa PROSAB Microbiologia. Os autores agradecem também o apoio da Companhia de Saneamento de Minas Gerais (COPASA) em fornecer as amostras de lodo ativado proveniente da Estação de Tratamento de Esgoto de Arrudas (ETE Arrudas).

\section{REFERÊNCIAS}

ALEXANDER, M.; CLARK, F.E. (1982) Nitrifying bacteria. In: BLACK, C.A. (Ed.). Methods of soil analysis. Part 2: Chemical and microbiological properties. Madison: American Society of Agronomy. p. 1477-1483.
AMANN, R.; LUDWIG, W.; SCHLEIFER, K. (1995) Phylogenetic identification and in situ detection of individual microbial cells without cultivation. Microbiology Reviews, v. 59, p. 143-169. DOI: 0146-0749/95/\$04.0010 
AMERICAN WATER WORKS ASSOCIATION (AWWA); AMERICAN PUBLIC HEALTH ASSOCIATION (APHA); WATER ENVIRONMENT FEDERATION (WEF). (2005) Standard Methods for Examination of Water and Waste Water, 21. ed. Washington, D.C.: American Public Health Association.

ARAÚJO, J.C.; CORREA, M.M.S.; SILVA, E.C.; CAMPOS, A.P.; GODINHO, V.; SPERLING, M.V.; CHERNICHARO, C.A.L. (2O10) Investigation of Aerobic and Anaerobic Ammonium-oxidizing bacteria presence in a small full-scale wastewater treatment system comprised by UASB reactor and three polishing ponds. Water Science Technology, v. 61, p. 737-743. DOI: 10.2166/wst.2010.955

BLACKBURNE, R.; VADIVELU, V.M.; YUAN, Z.; KELLER, Y. (2007) Kinetic characterization of an enriched Nitrospira culture with comparison to Nitrobacter. Water Research, v. 41, p. 3033-3042. https://doi.org/10.1016/j.watres.2007.01.043

DAIMS, H.; NIELSEN, P.; NIELSEN, J.L.; JURETSCHKO, S.; WAGNER, M. (2000) Novel Nitrospira-like bacteria as dominant nitrite-oxidizers in biofilms from wastewater treatment plants: diversity and in situ physiology. Water Science Technology, v. 41, p. 85-90.

JURETSCHKO, S.; TIMMERMANN, G.; SCHMID, M.; SCHLEIFER, K.H.; POMMERENING-RÖSER, A.; KOOPS, H.P.; WAGNER, M. (1998) Combined molecular and conventional analyses of nitrifying bacterium diversity in activated sludge: Nitrosococcus mobilis and Nitrospira-like bacteria as dominant populations. Applied and Environmental Microbiology, v. 64, p. 3042-3051.

KIELING, D.D. (2004) Estudo da remoção biológica de nitrogênio a partir de lodo nitrificante cultivado em meio autotrófico sob condições anóxicas. Dissertação (Mestrado) - Departamento de Engenharia Química e Engenharia de Alimentos, Universidade Federal de Santa Catarina.

KONUMA, S.; SATO, H.; MINO, T.; MATSUO, T. (2001) Comparison of enumerations methods for ammonia-oxidizing bacteria. Water Science and Technology, v. 43, n. 1, p. 107-114.
MATULEWICH, V.A.; STROM, P.F.; FINSTEIN, M.S. (1975) Length of incubation for enumerating nitrifying bacteria present in various environments. Applied and Environmental Microbiology, v. 29, p. 265-268.

MOBARRY, B.K.; WAGNER, M.; URBAIN, V.; RITTMAN, B.E.; STAHL, D.A. (1996) Phylogenetic probes for analysing abundance and spatial organization of nitrifying bacteria. Applied and Environmental Microbiology, v. 62, p. 2156-2162.

OLIVEIRA, S.M.C.; VON SPERLING, M. (2008) Reliability analysis of wastewater treatment plants. Water Research, v. 42, p. 1182-1194. DOI: 10.1016/j.watres.2007.09.001

REGINATTO, V.; TEIXEIRA, R.M.; PEREIRA, F.; SCHMIDELL, W: FURIGO JR., A.; MENES, R.; ETCHEBEHERE, C.; SOARES, H.M. (2005) Anaerobic ammonium oxidation in a bioreactor treating slaughter house wastewater. Brazilian Journal of Chemical Engineering, v. 22, n. 4, p. 593-600. http://dx.doi.org/10.1590/S010466322005000400012

SCHMIDT, I.; HERMELINK, C.; PAS-SCHOONEN, K.; STROUS, M.; CAMP, H.; KUENEN, J.G.; JETTEN, M.S.M. (2OO2) Anaerobic Ammonia Oxidation in the Presence of Nitrogen Oxides (NOX) by Two Different Lithotrophs. Applied and Environmental Microbiology, v. 68, p. 5351-5357. DOI: 10.1128/AEM.68.11.5351-5357.2002

TOH, S.K.; ASHBOLT, N.J. (2OO2) Adaptation of anaerobic ammoniumoxidising consortium to synthetic coke-ovens wastewater. Applied Microbiology and Biotechnology, v. 59, p. 344-352.

WAGNER, M.; RATH, G.; AMANN, R.; KOOPS, H.P.; SCHLEIFER, K.$\mathrm{H}$. (1995) In situ identification of ammonia-oxidizing bacteria. Systematic and Applied Microbiology, v. 18, p. 251-264. https://doi. org/10.1016/SO723-202O(11)80396-6

WAGNER, M.; RATH, G.; KOOPS, H.P.; FLOOD, J.; AMANN, R. (1996) In situ analysis of nitrifying bacteria in sewage treatment plants. Water Science Technology, v. 34, p. 237-244. https://doi.org/10.1016/02731223(96)00514-8 